\title{
EMOTIONALLY EVALUATING THE ATTITUDE OF CONSUMERS TOWARD SUPERVISION SERVICE
}

\author{
Maija Zakrizevska ${ }^{1}$
}

\begin{abstract}
This study is conducted because organization supervision in Latvia tends to rapidly take its proper place among other professions recognized on the national level and has become an inseparable part of professional activities, in particular in the areas focused on humans, for example: health care, art therapies, social and educational services, and the business environment. Given that the demand for supervisors continues to increase, the purpose of this study is the identification of the popularity and treatment of supervision service by consumers for the subsequent presentation of proposals to the administration of the Business Art and Technologies University RISEBA concerning the popularization of supervision services and improvement towards the Master Program "Management Psychology and Supervision". 111 respondents participated in the study, including respondents who have participated in supervision $(n=47)$ and respondents who have never participated in supervision $(n=64)$.

The study has led to the conclusion that the attitude of consumers toward supervision is generally positive. Most of the respondents have never been parties to supervision, yet a majority of the respondents would like to experience it. There are statistically significant differences between the attitudes toward supervision in the cognitive dimension.
\end{abstract}

UDC Classification: 159.9; DOI: http://dx.doi.org/10.12955/cbup.v5.1045

Keywords: supervision, supervision in business, attitude toward supervision

\section{Introduction}

Supervision is developing rapidly in Latvia and every year the Latvian Association of Supervisors certifies more supervisors who will work in various environments, and also as educators, to facilitate development of science in supervision. Three Latvian institutions of higher education offer a Master's Degree program for becoming a supervisor: The University of Business Arts and Technology RISEBA, Riga Stradins University, and the Latvian Christian Academy. All study programs comply with the standards applicable to the profession however, each of them is different in terms of the content, the degree awarded, and the annual tuition fee. It should be noted that the Latvian Union of Supervisors (www.supervizija.lv) includes 57 certified supervisors, has published three books and numerous articles about supervision, and two doctoral dissertations related to supervision have been defended. The only summarising collection of papers available in Latvian, titled "Supervizija teorija un prakse" ("Supervision Theory and Practice"), has been published (Mārtinsone, 2016). This is because in several professions nowadays, supervision has become a component of the professional practice and also education, whereas there is insufficient information about it in business. This is evidenced by the previously conducted study into the attitude of students and employers toward supervision already (Zakrizevska, 2016), which also explains the topicality of this study. The results of the study showed that, when hearing the words "supervision, supervisor," many employers have different emotionally evaluating attitudes and, for many of them, these may associate with in-service training, monitoring, and mentoring. It should also be noted that many consumers, including company managers and personnel managers, are still not informed about the actual benefits supervision provides in a business environment.

\section{Literature review}

Attitudes of consumers are widely being researched not only in social psychology, but also in business and marketing. This can be seen well in the following papers: Event Marketing and Attitude Changes (Nufer, 2016), Attitude of Latvian Consumers Toward Genetically Modified Organisms (Aleksejeva, 2016), Situational Influences on Consumers' Attitudes and Behaviour (Foxall, Yani-de-Soriano, 2005), Customers' Attitude Towards Plastic Money (Jain, 2016).

Attitude is a relatively stable, positively or negatively evaluating response which influences and motivates the behaviors associated with them (Olson, Maio, 2003). It may be targeted at a certain individual or events, at various things as well as at abstract objects, it helps the individual carry out an evaluation of an object or event, adapt to the environment and express their feelings or beliefs to others (Nevid, 2014). Attitude has an evaluating tendency, and it is this evaluating element which distinguishes attitude from belief (Davey G., 2006), which can be measured by contrast signs: good - bad, pleasant -

\footnotetext{
${ }^{1}$ University of Business, Arts and Technology RISEBA, maija.zakrizevska@ @iseba.lv
} 
unpleasant (Ajzen 2001). Attitude has three dimensions, they show in a wide spectrum the ways attitude may manifest in an individual (Smith, 1947, Rosenberg, Hovland C.I., 1960, Ya Hui, Petty, 2013). The three dimensions (or components) of attitude are formed by cognitive (knowledge about an environment object), emotional (emotional evaluation of the object) and behavioral reactions to an object (purposeful action with regard to the object) (Chaiken S, Pomerantz E.M., Giner-Sorolla R. 1995). Thus, attitude is defined as views regarding the achievement of certain targets, including understanding them, evaluation and a readiness to act (Schwarz, Bohner, 2001). Emotional attitude largely differs from, for instance, cognitive attitude, because it may often not be logical or based on facts. Behavioural reaction, in its turn, may vary depending on the actions of the surrounding people, because the individual may go with the majority and act the way they do despite their knowledge and emotions being in contrast to the behavior. It may be assumed that attitude can also be caused by false knowledge about an object.

Considering that studies of attitude are popular and particularly widespread in business and in science. This study into attitudes towards supervision may the attitudes of consumers towards supervision in all three dimensions (emotional, cognitive and behavioral), which might help to find out not only the emotionally evaluating attitudes, but also knowledge and readiness to use the service of supervision.

The aim of the study is to explore the attitudes of consumers towards supervision in order to give recommendations to the administration of RISEBA University of Business, Arts and Technology to popularise the supervision service and improve the Master's Degree program "Management Psychology and Supervision."

The research questions were the following: What is the emotionally evaluating attitude of consumers towards supervision? Are there statistically significant differences in the attitudes towards supervision between consumers with experience in supervision and consumers with no experience in supervision?

A reason for negative attitudes is frequently a lack of information, and it is therefore essential to study the attitudes of consumers and provide consumers with information through the questioning of individual views and values. Communication and types of communication are essential, as they assure positive attitudes among the beneficiaries. The creation of new needs and expectations by justifying it with the benefits to be achieved and assuring, and understanding that change of attitudes may change the current environment. Also, to change the attitudes of consumers it is necessary to understand the individual influencing factors. Change of attitudes may be used to popularise supervision in the business environment, which is a determinant of the topicality of this study.

\section{Methodology}

All three dimensions of attitude towards supervision are compared in the study: emotional, cognitive, and behavioral the links between each of them. Thus, it is possible to find out the effective attitude towards supervision, what the knowledge of both research samples about supervision is, and what behaviors in association with supervision each of the research samples has, simultaneously finding out whether there are any differences between the results of both samples and what these differences are. The survey consisted of 23 statements which were evaluated on a Likert-type scale with four values. (Likert-type scales)

142 questionnaires were obtained in total, of which 111 questionnaires were suitable for data processing. 31 questionnaires were incompletely filled in and, therefore, were not included in the mathematical and statistical analysis. No supervisors or supervision students were involved in the study.

The survey was completed by a total of 47 respondents who had participated in supervision and 64 respondents who have never taken part in supervision. Most of the respondents were from social work (29\%) and the state and local government sector (12\%), which totals to $40 \%$. The next largest group with $21 \%$ is the business sector, $18 \%$ represent the sector of education, $8 \%$ represent project management, $4 \%$ represent psychology, and $18 \%$ represent other, unspecified areas. In terms of the length of service, the job experience of $62 \%$ of the respondents exceeds 6 years, and this is the majority of the respondents, the job experience of $22 \%$ of the respondents is up to 4 years, and, for $16 \%$ of the respondents, their job experience is between 4 and 6 years. In terms of the position, $68 \%$ of the respondents, which is the majority, do not have managerial positions, while $32 \%$ of the respondents do have managerial positions. 
The questionnaire of the survey was created on the "webrpoolsurveys" platform and sent out to the respondents electronically as a link. The respondents could complete the survey questionnaire in November and December 2016.

The data collected during the survey were analyzed using Microsoft Excel and IBM SPSS 23.0 statistical data processing software.

\section{Results}

The data collected during the survey were analyzed using quantitative statistical research methods as well as methods of mathematic statistics to calculate data credibility or the Cronbach's alpha coefficient, correspondence of the data to normal distribution and determine the central tendency indicators for the data as well as the statistically significant differences.

To verify the credibility of the designed questionnaire regarding supervision, the Cronbach's alpha (or the Consistency Coefficient) was calculated. It shows whether the statements are adequately and mutually consistent within each particular scale and within the entire survey (see Table 1).

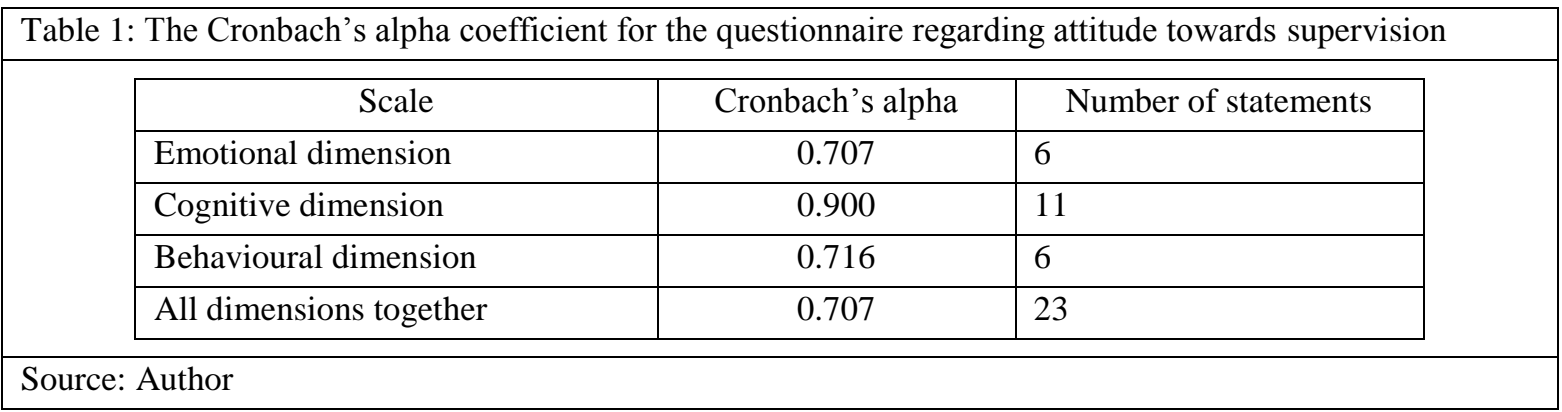

The aggregate Cronbach's coefficient alpha for all the dimensions can be rated as very good (see Table 1), which means that the results obtained during the survey are credible and can be used for further data analysis and interpretation.

To determine the central tendency indicators, the Kolmogorov-Smirnov $\mathrm{Z}$ criterion was calculated, thus determining the significance of these scales. It shows the correspondence to the normal distribution and also what the methods to be used for the further processing of the data should be. The results of the calculation lead to the conclusion that the significance is below 0.05 for the emotional dimension and behavioral dimension scales, which means that the values of these scales do not correspond to the normal distribution, whereas the significance value for the cognitive scale is 0.200 , and it corresponds to the normal distribution.

The survey was completed by the total of 47 respondents who had participated in supervision and 64 respondents who have never taken part in supervision. Since, based on the result of the T-test, the significance for these samples is below 0.05 , it is confirmed that there are statistically significant differences in the cognitive or knowledge dimension between the respondents who have participated and those who have not participated in supervision (see Table 2).

\begin{tabular}{|l|l|c|c|c|}
\hline \multicolumn{6}{|l|}{ Table 2: Differences in attitudes towards supervision in the cognitive dimension: experience in supervision } \\
\hline \multicolumn{2}{|c|}{ Cognitive dimension } & Arithmetical mean & $\mathrm{t}$ & Significance \\
\hline $\begin{array}{l}\text { Have participated in the } \\
\text { supervision }\end{array}$ & 18.6170 & -7.522 & 0.000 \\
\hline $\begin{array}{l}\text { Have never taken part in } \\
\text { supervision }\end{array}$ & 26.6250 & -7.399 & 0.000 \\
\hline
\end{tabular}

\section{Source: Author}

According to the Mann-Whitney U test, which was used to study the potential differences between the respondents in the above-mentioned groups (respondents who have participated in supervision and respondents who have not participated supervision), there are no statistically significant differences in the emotional and behavioural dimension (the significance is above 0.05) (see Table 3). 
Table 3: Differences in attitudes towards supervision in the emotional and behavioral dimension: experience in supervision

\begin{tabular}{|l|l|l|l|}
\hline \multirow{4}{*}{} & Scale & $\mathrm{U}$ & Significance \\
\cline { 2 - 4 } & Emotional dimension & $1,475.50$ & 0.864 \\
\cline { 2 - 4 } & Behavioural dimension & $1,469.50$ & 0.836 \\
\hline \multicolumn{2}{|l}{} \\
\hline
\end{tabular}

All respondents were asked the question: Do you have a positive attitude towards supervision? The majority of the respondents $(79 \%)$ have a positive emotionally evaluating attitude towards supervision. Still, $21 \%$ of the respondents had a negative emotionally evaluating attitude towards supervision, which suggests certain negative experience in association with supervision (see Figure 1).

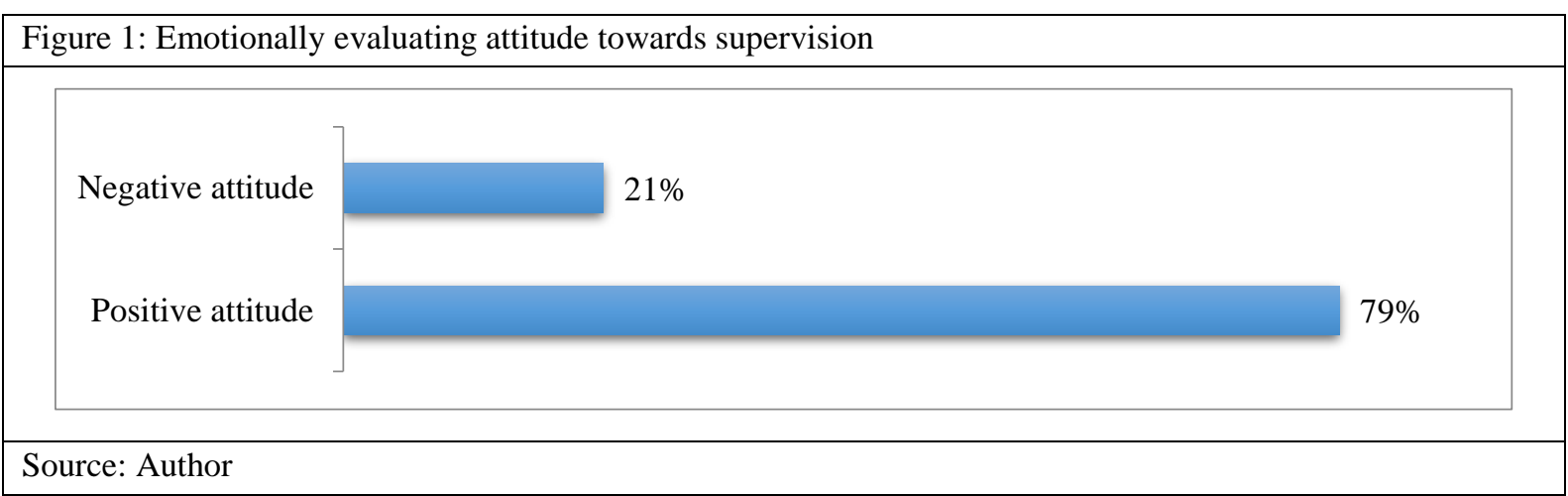

The obtained results suggest that attitudes towards supervision are more negative among those who have participated (28\%) in supervision (see Figure 2). This might mean negative experience with regard to the supervision service.

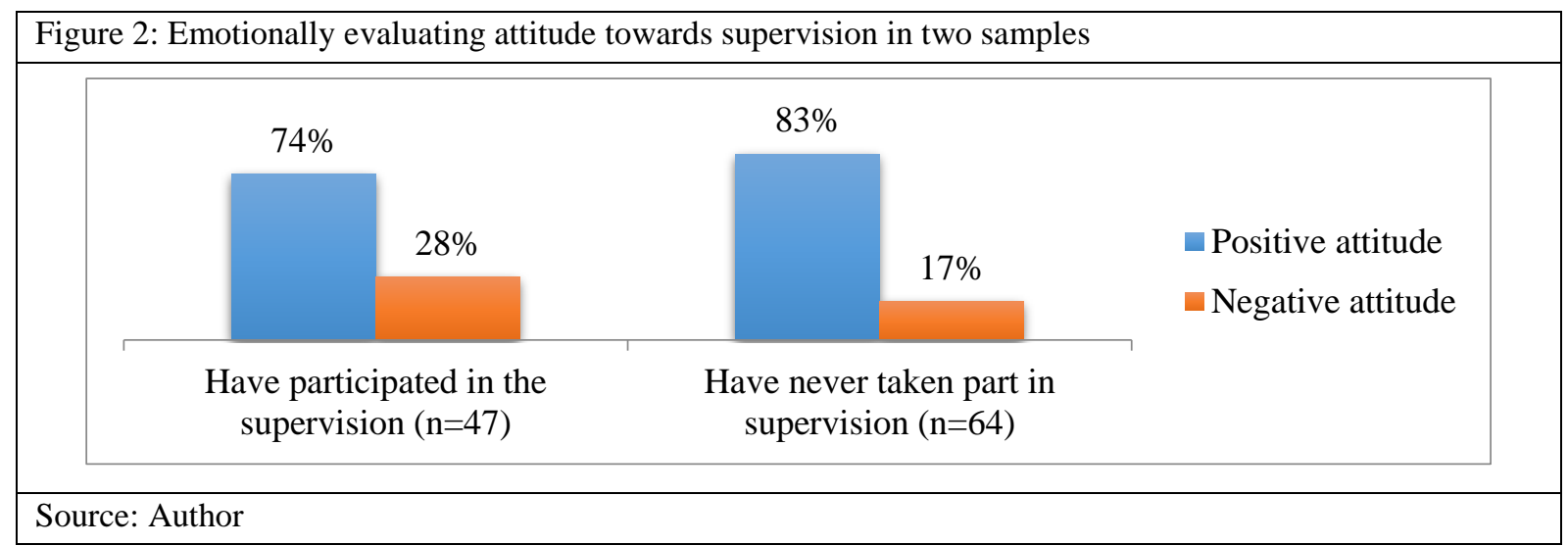

The results of the survey show positive emotionally evaluating attitudes of consumers towards supervision and also that supervision is popular among consumers, as $71 \%$ of the respondents know what supervision is, $64 \%$ of the respondents know where to find information about supervision, and the majority of the respondents (73\%) would be able to explain what supervision is if asked by a friend. $42 \%$ of the respondents have participated in supervision.

The results of the survey also show that the majority or $63.6 \%$ of the respondents claim that they understand the process of supervision; approximately one half or $49 \%$ of the respondents have no knowledge about how to organise a supervision session; $85.6 \%$ of the respondents are ready to attend a supervision session if necessary, but others would most likely not do it; almost one half or $47.7 \%$ of the respondents are not ready to pay for supervisor services as part of their job.

The obtained results show positive tendencies in the development of the supervision service. Although the service is becoming more popular, almost one half of the respondents are not willing to pay for it themselves. This means that consumers have not been made aware of the benefits supervision provides. 


\section{Conclusions and Recommendations}

The conducted survey is significant for the development of supervision as a sector, and the obtained results show the attitudes of consumers in two samples.

Although the emotionally evaluating attitudes of consumers are generally positive, there is knowledge about supervision and readiness to use the supervision service, consumers are not ready to pay for it and do not know how to organize a supervision session in case it was necessary.

There are statistically significant differences in the cognitive or knowledge dimension between the respondents who have participated in supervision and those who have not participated in supervision, and this suggests that those who have participated in supervision have knowledge about supervision.

When comparing the results of the two samples, i.e., the emotionally evaluating attitudes of the respondents who have participated in supervisions and the respondents who have not participated in supervisions, it can be concluded that those who have participated in supervisions (28\%) have more negative attitudes, and this might be suggestive of negative experience with regard to the supervision service.

The obtained results and the conclusions drawn allow to give the following recommendations to the management of the Master's Degree program "Management Psychology and Supervision" of RISEBA University of Business, Arts and Technology:

Attitudes are related to the experience with supervision one has had. It can be assumed that the consumers who have received the supervision service are not satisfied with it and, consequently, are avoiding or will be avoiding group and team supervisions. Therefore, it is essential to provide a quality supervision service by preparing highly qualified specialists - supervisors.

It is necessary to continue to promote the supervision service in mass media and social networks, laying particular emphasis on the benefits of supervision for employees and managers. For example, by giving interviews and preparing publications for various popular science magazines.

\section{References}

Ajzen, I. (2001). Nature and operations of attitudes, Annual Review of Psychology, 52, 27-58.

Aleksejeva, I. (2016). Latvijas patērētāju attieksme pret ǵenētiski modificētiem organism. [Latvian consumers' attitude towards genetically modified organisms]. Riga: Latvian University, Faculty of Economics and Management.

Chaiken, S., Pomerantz, E.M., \& Giner-Sorolla, R. (1995). Structural consistency and attitude strength. In R.E. Petty \& J.A. Krosnick [Editorial]. Attitude strength: Antecedents and and consequences, Mahwah, NJ: Erlbaum, 387-412.

Davey, G. (2006). Encyclopaedic dictionary of psychology. Publisher: Routledge

Rosenberg, M.J., Hovland, C.I. (1960). Cognitive, affective and behavioural components of attitude. In M. Rosenberg \& C. I. Hovland [Editorial]. Attitude organization and change. New Haven: Yale University Press, 1 - 14.

Foxall, G. R., Yani-de-Soriano, M. M. (2005). Situational influences on consumers' attitudes and behavior. Journal of Business Research, 58 (4), 518-525.

Jain, S. (2016). Custumer`s Attitude Towards Plastic Money. Management Strategies Journal, 32 (2), 79-82.

Mārtinsone, K. (2016). Supervīzija: teorija un prakse [Supervision: Theory and Practice]. K. Mārtinsone [Editorial]. Riga: Riga Stradins University.

Nevid, J.S. (2014). Essentials of Social Psychology. Concepts and Aplications, Stamford: Cengage Learning, 557.

Nufer, G. (2016). Event Marketing and Attitude Changes. Journal of International Business Research and Marketing, 1 (3), 44-49.

Olson, J. M., Maio, G. R. (2003). Attitudes in social behavior. In T. Millon \& M. J. Lerner [Editorial]. Comprehensive handbook of psychology: Personality and Social Psychology Hoboken, NJ: Wiley, (5), 299-325.

Schwarz, N., Bohner, G. (2001). The Construction of Attitudes. In A. Tesser, N. Schwarz [Editorial]. Intrapersonal Processes (Blackwell Handbook of Social Psychology), Oxford, UK: Blackwell, 436-457.

Zakrizevska, M. (2016). Business students and employers attitude towards supervision. Rural Environment. Education. Personality. Proceedings of the 9th International Scientific Conference, 9, 283 - 295.

Ya Hui, M., Petty, R. E., Fabrigar, L. R. (2013). Affective-Cognitive Meta-Bases Versus Structural Bases of Attitudes Predict Processing Interest Versus Efficiency, Personality and Social Psychology Bulletin, 39 (8), 1111-1123. 